Dicle Üniversitesi Veteriner Fakültesi Dergisi
https://dergipark.org.tr/tr/pub/duvetfd
Araştırma Makalesi/Research Article
Dicle Üniv Vet Fak Derg 2021;14(2):107-112
DOl: 10.47027/duvetfd.986911

\title{
Sivas İli Manda İşletmelerinde Karma Üretim Durumunun ve Yetiştirici Eğitim Gereksinimlerinin Belirlenmesi
}

\author{
Gökçe ÖZDEMiR ${ }^{1, a, \bigotimes}$
}

${ }^{1}$ Sivas Cumhuriyet Üniversitesi, Veteriner Fakültesi, Zootekni Anabilim Dalı, Sivas, TÜRKiYE

aORCID: 0000-0003-1977-130X

\begin{tabular}{ccc}
\hline Geliş Tarihi/Received & Kabul Tarihi/Accepted & Yayın Tarihi/Published \\
25.08 .2021 & 30.09 .2021 & 31.12 .2021 \\
\hline
\end{tabular}

Öz

Manda, süt ve et ürünlerinin kalitesi, sığırlara göre hastalıklara daha dayanıklı olması, kalitesiz kaba yemleri kaliteli süt ve et ürünlerine dönüştürebilmesi, yetiştirme maliyetinin düşük olması gibi nedenlerle ekonomik bir çiftlik hayvanıdır. Bu çalışmada, Sivas ili Merkez, Şarkışla ve Suşehri ilçelerinde 20 köydeki toplam 122 manda yetiştiricisine uygulanan anket verileri sunuldu. Katılımcıların \%60'dan fazlasının 15-20 yılı aşkın bir süredir manda yetiştiriciliği ile uğraştıkları belirlenmiştir. Manda yetiştiriciliği dışında katılımcıların, \%5.7'si sadece büyükbaş hayvan yetiştiriciliği, \%54.9'u kanatlı ve büyükbaş hayvan yetiştiriciliği, \%27.9'u bitkisel üretim ve büyükbaş hayvan yetiştiriciliği yaptıklarını ve \%7.4'ü sadece bitkisel üretim ile uğraştıklarını beyan etmişlerdir. Iş̧letmelerde montofon, simental ve bunların melezi sığırların yetiştirildiği tespit edildi. Katılımcıların \%34.7'sinin manda yetiştiriciliği konusunda il/ilçe müdürlüklerinden bilgi edinirken, yalnızca \%2.5 inin doğrudan profesyonel yardım (veteriner hekim, ziraat mühendisi) aldığı belirlendi. Üreticilerin \%68.9'u manda yetiştiriciliği hakkında bir eğitim düzenlenirse katılmak istediklerini ifade ettiler. Sonuç olarak; yetiştiricilerin yeterli bir bilgiye ve eğitime ulaşamadıkları, eğitime hevesli oldukları, manda üretimi, verimliliği ve davranışları konularında bilgi birikimlerinin geliştirilmesine yönelik eğitim programlarının düzenlenmesinin faydalı olacağı kanatine varılmıştır.

Anahtar Kelimeler: Eğitim, karma üretim, manda yetiştiriciliği, sığır

Determination of Mixed Production Status and Breeder Training Requirements in Buffalo Businesses in Sivas Province

Abstract

Water buffalo breeding has an important place because it is an economical farm animal due to the quality of milk and meat products, being more resistant to diseases than cattle, superior ability to benefit from feed, converting poor quality roughage into quality milk and meat products, and low breeding costs. In this study, survey data applied to a total of 122 water buffalo breeders in 20 villages in Sivas Province Centre, Şarkışla and Suşehri districts were presented. It has been determined that more than $60 \%$ of the participants have been dealing with buffalo breeding for more than 15-20 years. Except for buffalo breeding, $5.7 \%$ of the participants stated that they only do cattle breeding, $54.9 \%$ poultry and cattle breeding, $27.9 \%$ vegetal production and cattle breeding, and $7.4 \%$ only plant production. It was determined that montofon, simental and their hybrid cattle were raised in the farms. It was determined that $34.7 \%$ of the participants obtained information about buffalo breeding from the provincial/district directorates, while only $2.5 \%$ of them received direct professional help (veterinarian, agricultural engineer). $68.9 \%$ of the producers stated that they would like to participate if a training was organized on buffalo breeding. As a result; It has been concluded that the breeders cannot reach sufficient information and education, they are eager for education, and it would be beneficial to organize training programs to improve their knowledge on water buffalo production, productivity and behavior.

Key Words: Training, mixed production, water buffalo breeding, cattle

\section{Giriş}

Manda, önemli bir kısmı Asya kıtasında bulunan (\%96.4), süt, et, deri ve iş gücünden yararlanmak üzere yetiştiriciliği yapılan, Bovidae ailesine mensup bir türdür. Mandanın hayvancılıktaki önemi, sığırlarla kıyaslandığında hastalıklara dayanıklı olması, yemden yararlanma kabiliyetlerinin daha üstün olması, kalitesiz kaba yemleri kaliteli süt ve et ürünlerine dönüştürebilmesi, yetiştirme maliyetinin düşük olması gibi nedenlerle ekonomik bir çiftlik hayvanı olmasından gelmektedir (1-4). Manda sahip olduğu üstünlükler ile yetiştiriciler arasında üretim alışkanlığı olarak, kaliteli ürünlerinin varlığıyla da tüketiciler arasında vazgeçilmez olarak görülmekte$\operatorname{dir}(1,5)$.

Geçmişten günümüze Anadolu Mandası, Türkiye için önemli bir üretim kaynağı olmuştur. Manda yetiştiriciliği, sürdürülebilir üretim, kırsal kalkınma ve yerli gen kaynaklarının korunması amacıyla yürütülen çalışmalar sonucunda varIığını devam ettirmiştir $(6,7)$. Türkiye'de, manda yetiştiriciliğinde belli başlı bölgeler ve bazı iller dikkat çekmektedir. Kuzey Anadolu kıyı şeridinde Samsun ve Orta Anadolu'nun kuzeyinde Tokat, Güney Doğu Anadolu'da Diyarbakır, Trakya 
bölgesinde İstanbul manda nüfusu fazla olan illerdir. Sivas, Kayseri, Afyon, Bitlis, Muş gibi bazı illerde de et ve süt üretimi amaçlı manda yetiştiriciliği devam ettirilmektedir $(6,8)$. Türkiye'de manda yetiştiriciliğinin, önemli bir kısmı (\%83) geleneksel aile tipi, küçük ölçekli (1-5 baş) işletmelerde, az bir bölümü (\%17) ise orta ölçekli ( 8 baş ve yukarı) işletmelerde yürütülmektedir (9).

Sivas ili, 2009 yılı manda varlığı 1.807 baş iken, manda yetiştiriciliğinin geliştirilmesi amacıyla kamu, birlik ve üniversite kapsamında gerçekleştirilen çalışmalar sonucunda Türkiye genelindeki manda sayısındaki artış, Sivas iline de yansımış ve 2018 yılı itibariyle manda sayısı 5.771 başa yükselmiştir (10). Geniş meraları ve coğrafi yapısı ile Sivas ili manda sayısı bakımında Türkiye genelinde 9. sırada yer almaktadır (10).

$\mathrm{Bu}$ çalışmada; manda işletmelerindeki mevcut durumun yerinde tespit edilmesi, işletmelerdeki manda dışındaki karma üretim (kanatlı, büyükbaş, küçükbaş hayvan yetiştiriciliği, bitkisel üretim) durumunun araştırılması, mandayı farklı kılan yönleri ve yetiştiricilerin eğitim düzeyi ile gereksinimlerinin ortaya konması amaçlandı.

\section{MATERYAL VE METOT}

Bu araştırmanın ana materyali; Sivas ili manda yetiştiriciliğinin yoğun olarak yapıldığı Merkez, Şarkışla ve Suşehri ilçelerine bağı köylerde faaliyet gösteren 177 manda işletmesi arasından Tabakalı Örnekleme Yöntemine göre belirlendi. Örneklem büyüklüğü, Merkez ilçe için 68, Şarkışla için 15 ve Suşehri için 39 işletme olarak hesaplandı (11). Çalışmanın anket soruları daha önce yapılan çalışmalardan faydalanılarak geliştirildi $(5,12)$. Merkez, Şarkışla ve Suşehri ilçelerine bağlı 20 yerleşim biriminde faaliyet gösteren toplam 122 manda yetiştiricisine birebir ulaşılarak, yerinde yüz yüze yapılan anket uygulaması sonucunda, çalışmaya ait veriler toplandı. Bu çalışmada; hayvanların bakımıyla ilgilenen kişiler, manda yetiştiricilik amaçları, işletmedeki hayvan sayıları, işletmelerde yetiştirilen sığır ırkları gibi bilgileri elde etmek üzere katılımcılara yöneltilen toplam 15 sorunun verileri sunuldu. Araştırmada elde edilen veriler, SPSS 17.0 paket programı (13) kullanılarak, ilçeler bazında $\left(r^{*} c\right)$ soru maddeleri arasındaki ilişkiler önemli olup olmadığı Ki-Kare $\left(X^{2}\right)$ bağımsızlık testi ile analiz edildi. Sonuçlar, çapraz tabloların analizlerinden yararlanılarak, tanımlayıcı istatistikler (frekans ve yüzde oran) şeklinde sunuldu (11).

\section{BULGULAR}

İşletmelerin hayvan varlığı, hayvanların bakımı ile ilgilenen kişi sayıları, yetiştiricilerin tecrübeleri ile yetiştiricilik amaçlarına ait bilgiler Tablo 1'de sunulmuştur. Ankete katılan işletme içerisinde 1-10 baş mandaya sahip işletmelerin oranı \%6.4, 11 baş ve üzeri mandaya sahip olan işletmelerin oranı ise \%35.5 olarak belirlendi. Bu işletmelerin ortalama \%70'nin 11 baş ve üzeri sığır varlığına sahip oldukları tespit edildi $(p<0.05)$. İşletmelerin \%91'nde hayvanların bakımı ile hane halkının ilgilendiği tespit edildi. Hayvan bakımıyla ilgilenen kişi sayısı ise sırasıyla \%83.5'i 1-3 kişi, \%15.7'si 4-6 kişi olduğu belirlendi $(p<0.01)$. Tablo 1'de görüldüğü üzere işletmelerin (\%98.4) aile işgücü ile desteklendiği tespit edildi. Katılımcılar ortalama \%60.7'si 21 yıl ve üzeri, \%4.9'u 5 yıldan az süredir manda yetiştiriciliği ile uğraştıkları saptandı. Katılımcıların \%42.6'sı süt üretimi amacıyla manda yetiştiriciliği yaparken, \%57.4'ü et ve süt kombine üretimi amaçladıkları saptandı $(p<0.01)$. Tablo $1^{\prime}$ de belirtildiği üzere işletmelerin \%95.1'nin özellikle manda yetiştiriciliği ile birlikte sığır yetiştiriciliği de yaptıkları tespit edildi $(p<0.05)$.

Tablo 1. İşletmelere ait genel bilgiler

\begin{tabular}{|c|c|c|c|c|c|c|c|c|c|c|c|}
\hline \multirow{3}{*}{ Sorular } & \multirow{2}{*}{\multicolumn{2}{|c|}{ Parametreler }} & \multirow{2}{*}{\multicolumn{2}{|c|}{ Merkez }} & \multirow{2}{*}{\multicolumn{2}{|c|}{ Şarkışla }} & \multirow{2}{*}{\multicolumn{2}{|c|}{ Suşehri }} & \multirow{2}{*}{\multicolumn{2}{|c|}{ Toplam }} & \multirow{3}{*}{ p } \\
\hline & & & & & & & & & & & \\
\hline & & & $\mathbf{n}$ & $\%$ & $\mathbf{n}$ & $\%$ & $\mathrm{n}$ & $\%$ & $\mathbf{n}$ & $\%$ & \\
\hline \multirow{6}{*}{ İşletmedeki hayvan sayısı } & \multirow{3}{*}{$\begin{array}{l}\frac{\pi}{0} \\
\frac{1}{2} \\
\sum \\
\sum\end{array}$} & $1-5$ baş & 20 & 29.4 & 8 & 53.3 & 11 & 28.9 & 39 & 32.2 & - \\
\hline & & $6-10$ baş & 26 & 38.2 & 3 & 20 & 10 & 26.3 & 39 & 32.2 & \\
\hline & & 11 baş ve daha fazla & 22 & 32.4 & 4 & 26.7 & 17 & 44.7 & 43 & 35.5 & \\
\hline & \multirow[b]{3}{*}{$\sqrt[3]{\sqrt[3]{n}}$} & $1-5$ baş & 4 & 6.3 & 2 & 13.3 & 10 & 27 & 16 & 13.8 & * \\
\hline & & $6-10$ baş & 8 & 12.5 & 3 & 20 & 8 & 21.9 & 19 & 16.4 & \\
\hline & & 11 baş ve daha fazla & 52 & 81.3 & 10 & 66.7 & 19 & 51.4 & 81 & 69.8 & \\
\hline \multirow[t]{3}{*}{ Hayvanların bakımıyla ilgilenen kişiler } & \multicolumn{2}{|c|}{ Kendim } & 8 & 11.8 & - & - & 1 & 2.6 & 9 & 7.4 & - \\
\hline & \multicolumn{2}{|c|}{ Hane Halkı } & 59 & 86.8 & 14 & 93.3 & 38 & 97.4 & 111 & 91 & \\
\hline & \multicolumn{2}{|c|}{ Hayvan Bakıcısı } & 1 & 1.5 & 1 & 6.7 & - & - & 2 & 1.6 & \\
\hline \multirow[t]{4}{*}{ Hayvanlarla ilgilenen kişi sayısı } & \multicolumn{2}{|l|}{$1-3$} & 54 & 80.6 & 9 & 60 & 38 & 97.4 & 101 & 83.5 & $* *$ \\
\hline & \multicolumn{2}{|l|}{$4-6$} & 12 & 17.9 & 6 & 40 & 1 & 2.6 & 19 & 15.7 & \\
\hline & \multicolumn{2}{|l|}{$7-9$} & - & - & - & - & - & - & - & - & \\
\hline & \multicolumn{2}{|c|}{$10>+$} & 1 & 1.5 & - & - & - & - & 1 & 0.8 & \\
\hline \multirow[t]{5}{*}{ Ne zamandan beri, manda yetiştiriciliği ile uğraşıyorsunuz? } & \multicolumn{2}{|c|}{5 yıldan az } & 4 & 5.9 & 1 & 6.7 & 1 & 2.6 & 6 & 4.9 & - \\
\hline & \multicolumn{2}{|c|}{$6-10$ yıl arası } & 10 & 14.7 & 2 & 13.3 & 11 & 28.2 & 23 & 18.9 & \\
\hline & \multicolumn{2}{|c|}{$11-15$ yıl arası } & 9 & 13.2 & 3 & 20 & 2 & 5.1 & 14 & 11.5 & \\
\hline & \multicolumn{2}{|c|}{$16-20$ yıl arası } & 3 & 4.4 & 2 & 13.3 & - & - & 5 & 4.1 & \\
\hline & \multicolumn{2}{|c|}{21 yıl ve üzeri } & 42 & 61.8 & 7 & 46.7 & 25 & 64.1 & 74 & 60.7 & \\
\hline \multirow[t]{3}{*}{ Manda yetiştiriciliği amacınız } & \multicolumn{2}{|c|}{ Besi (Et) } & - & - & - & - & - & - & - & - & $* *$ \\
\hline & \multicolumn{2}{|l|}{ Süt } & 36 & 52.9 & 7 & 46.7 & 9 & 23.1 & 52 & 42.6 & \\
\hline & \multicolumn{2}{|c|}{ Kombine (Et-Süt) } & 32 & 47.1 & 8 & 53.3 & 30 & 76.9 & 70 & 57.4 & \\
\hline \multirow[t]{2}{*}{ İşletmenizde manda ile sığır birlikte mi? } & Evet & & 65 & 95.6 & 14 & 93.3 & 37 & 94.6 & 116 & 95.1 & $*$ \\
\hline & Hay & & 3 & 4.4 & 1 & 6.7 & 2 & 5.1 & 6 & 4.9 & \\
\hline
\end{tabular}


Katılımcıların manda yetiştiriciliği dışında uğraşı alanı Grafik 1'de sunulmuştur.

Grafik 1. Manda yetiştiriciliği haricindeki üretim faaliyetleri

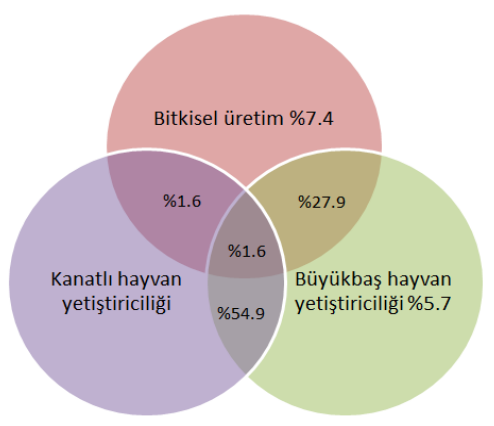

Manda yetiştiricilerin 7.4'ü sadece bitkisel üretim ile uğraştıkları; \%30'u bitkisel üretimin yanı sıra kanatlı ve büyükbaş hayvan yetiştiriciliği de yaptıkları belirlendi. Katılımcıların \%5.7'sinin sadece büyükbaş hayvan yetiştiriciliği yaptıkları ve \%54.9'unun ise kanatlı ile birlikte büyükbaş hayvan yetiştiriciliği ile uğraştıkları saptandı.

Manda yetiştiriciliği yapan işletmelerin \%95'i sığır yetiştiriciliği de yaptığı saptandı. İşletmelerde bulunan sığır ırkları Grafik 2'de sunulmuştur.

Grafik 2. İşletmelerde yetiştirilen sığır ırkları

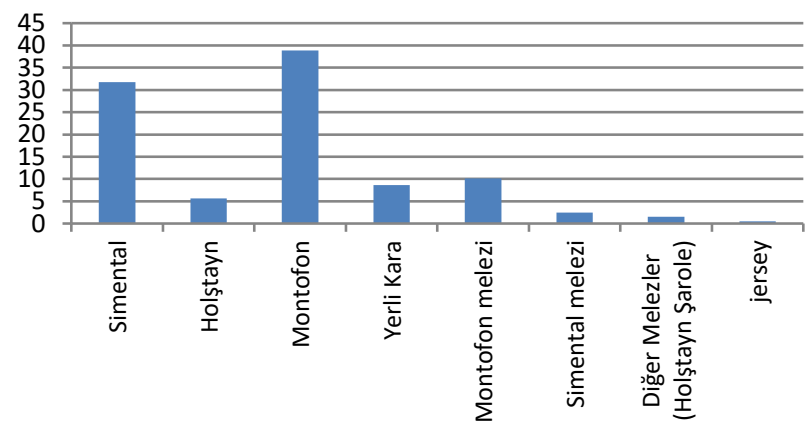

Grafik 2'de verildiği üzere işletmelerdeki sığır ırklarının dağılımı, Sivas ili büyükbaş hayvan varlığını yansıtır şekilde işletmelerin; Montofon (\%38.9), Simental (\%31.8), Holştayn (\%5.6) ırkı ile bu ırkların melezlerini (\%14.1) yetiştirdikleri belirlendi $(p<0.05)$

Sığır ırklarını tercih etme nedenleri Grafik 3'te sunulmuştur.
Grafik 3. Yetiştiricilerin sığır ırklarını tercih etme nedenleri

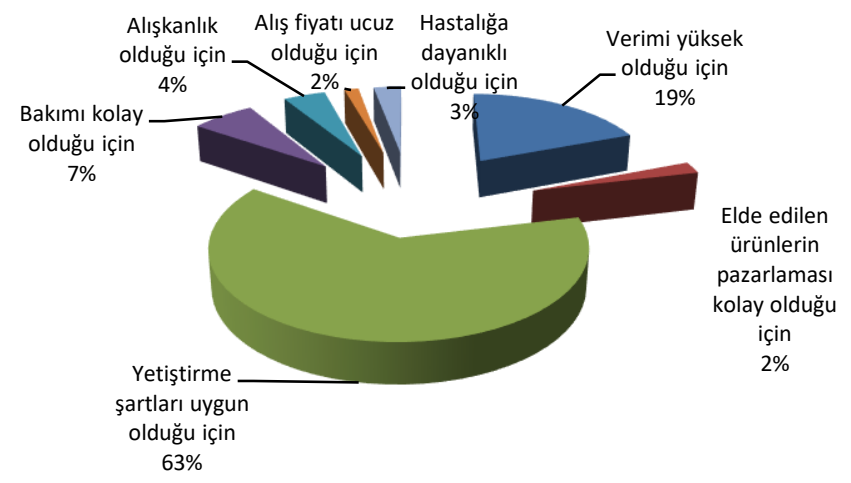

Grafik 3'te belirtildiği üzere, ağırlıklı olarak montofon, simental ve bu ırkların melezlerini yetiştiren katılımcıların özellikle yetiştirme şartlarına uygun (\%63), verimlerinin yüksek (\%19) ve bakımlarının da kolay olması gibi gerekçelerle bu ırkları tercih ettikleri tespit edildi $(p<0.01)$.

Katılımcıların sığır ile karşılaştırıldığında manda yetiştiriciliğinin farklılıkları konusunda "Manda sütü ve ürünleri kaliteli, fiyatı da yüksek ama miktarı az" (Merkez: \%26.7; Şarkışla: \%28.6; Suşehri: \%26.1) yönünde ortak bir görüşe sahip oldukları saptandı (Grafik 4).

Grafik 4. Sığır yetiştiriciliği ile karşılaştıııldığında manda yetiştiriciliğinin farklııkları

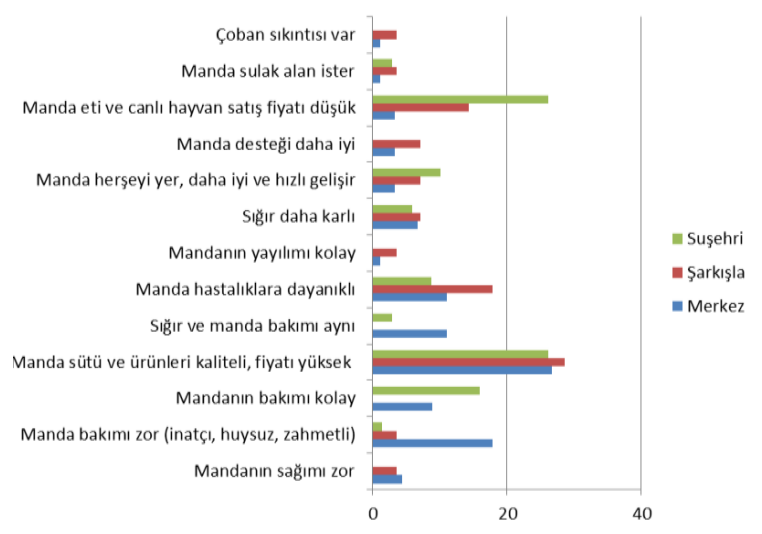

Katılımcıların hayvancılık ile ilgili toplantı-eğitime katıIım durumları ile bilgilere ulaşma kaynaklarını belirlemeye yönelik sorulara ait veriler Tablo 2' de sunulmuştur.

Tablo 2. Katılımcıların hayvancılık ile ilgili toplantı-eğitime katılım durumu ile yenilik ve bilgilere ulaşma kaynakları

\begin{tabular}{|c|c|c|c|c|c|c|c|c|c|c|}
\hline \multirow[t]{2}{*}{ Sorular } & \multirow[t]{2}{*}{ Parametreler } & \multicolumn{2}{|c|}{ Merkez } & \multicolumn{2}{|c|}{ Şarkışla } & \multicolumn{2}{|c|}{ Suşehri } & \multicolumn{2}{|c|}{ Toplam } & \multirow[t]{2}{*}{$\mathbf{p}$} \\
\hline & & $\mathrm{n}$ & $\%$ & $\mathrm{n}$ & $\%$ & $\mathrm{n}$ & $\%$ & $\mathrm{n}$ & $\%$ & \\
\hline \multirow{2}{*}{ Manda ile ilgili toplantı ya da eğitime katıldınız mı? } & Evet & 26 & 38.2 & 5 & 33.3 & 15 & 38.5 & 46 & 37.7 & - \\
\hline & Hayır & 42 & 61.8 & 10 & 66.7 & 24 & 61.5 & 76 & 62.3 & \\
\hline \multirow{2}{*}{ Sığır ile ilgili toplantı ya da eğitime katıldınız mı? } & Evet & 9 & 13.2 & 2 & 13.3 & 9 & 23.1 & 20 & 16.4 & - \\
\hline & Hayır & 59 & 86.8 & 13 & 86.7 & 30 & 76.9 & 102 & 83.6 & \\
\hline \multirow{2}{*}{$\begin{array}{l}\text { Eğitim ya da toplantıların yetiştiricilik bilgilerinize kat- } \\
\text { kısı oldu mu? }\end{array}$} & Evet & 24 & 88.9 & 5 & 100 & 14 & 73.7 & 43 & 84.3 & - \\
\hline & Hayır & 3 & 11.1 & - & - & 5 & 26.3 & 8 & 15.7 & \\
\hline Eğitim düzenlenirse katılır mısınız? & Evet & 49 & 72.1 & 10 & 66.7 & 25 & 64.1 & 84 & 68.9 & - \\
\hline \multirow{8}{*}{$\begin{array}{l}\text { Hayvancılık hakkında yenilik ve bilgi kaynaklarına nere- } \\
\text { den ulaşıyorsunuz? }\end{array}$} & il/iliçe Müdürlükleri & 35 & 51.5 & 1 & 6.7 & 6 & 15.8 & 42 & 34.7 & $* * *$ \\
\hline & Aile & 8 & 11.8 & 7 & 46.7 & 25 & 65.8 & 40 & 33.1 & \\
\hline & Diğer Çiftçiler & 1 & 1.5 & - & - & 1 & 2.6 & 2 & 1.7 & \\
\hline & $\begin{array}{l}\text { TV/Gazete/Radyo/ } \\
\text { Internet }\end{array}$ & 9 & 13.2 & 4 & 26.7 & - & - & 13 & 10.7 & \\
\hline & Damızlık Birlikleri & 13 & 19.1 & 2 & 13.3 & 5 & 13.2 & 20 & 16.5 & \\
\hline & Bilgi Almıyorum & 1 & 1.5 & - & - & - & - & 1 & 0.8 & \\
\hline & Üniversite Mezunu (Ziraat Mühendisi) & 1 & 1.5 & - & - & 1 & 2.6 & 2 & 1.7 & \\
\hline & Veteriner Hekimler & - & - & 1 & 0.8 & - & - & 1 & 0.8 & \\
\hline
\end{tabular}

n: frekans, \%: yüzde, $* * *: p<0.0001,-; p>0.05$ 
Katılımcıların \%37.7'si manda yetiştiriciliği ile ilgili bir toplantı ya da eğitime katıldığını beyan ederken, sadece \%16.4'ü sığır yetiştiriciliği ile ilgili herhangi bir toplantı ya da eğitime katıldığını bildirdiler. Herhangi bir eğitime katılan üreticilerin \%84.3'ü katıldıkları eğitim ya da toplantıların yetiştiricilik bilgilerine katkısı olduğunu belirtirken, \%68.9'u manda yetiştiriciliği hakkında bir eğitim düzenlenirse katılmak istediklerini ifade ettiler. Katılımcıların \%34.7'sinin il/ilçe müdürlüklerinden manda yetiştiriciliği konusunda bilgi edinmeye çalışırken yalnızca \%2.5'inin doğrudan profesyonel yardım (veteriner hekim, ziraat mühendisi) aldığı belirlendi $(p<0.001)$.

\section{TARTIŞMA VE SONUÇ}

Ankete katılan işletmelerin \%64.4'ü 1-10 baş manda varlığına sahip iken, toplam işletmelerin \%35.5'i 11 baş ve üzeri mandaya sahip olduğu tespit edildi (Tablo 1 ). Sivas ili manda yetiştiriciliği, ülke genelinde olduğu gibi küçük ve orta ölçekli işletmelerde geleneksel bir yapıda gerçekleştirilmektedir. Bu yetiştiricilik kolunun gelişimi için işletmeler büyüme yönünde desteklenmelidir. Manda ürünlerine olan talep artışının bir sonucu olarak, son yıllarda işletme başına manda sayısında önemli bir artış olduğu, işletmelerin büyüme eğilimi içerisinde bulunduğu ve daha verimli sonuçlar elde edildiği bildirilmektedir $(4,7)$. İşletmelerin \%70'de manda yanında 11 baş ve üzeri sığır varlığına da sahip oldukları tespit edildi (Tablo 1). Sığır varlığı bakımından ilçeler arasındaki farklılıklar önemli bulundu $(p<0.05)$. İşletmelerin sığır yetiştiriciliğine daha fazla eğilim içerisinde oldukları ortaya kondu.

İşletmelerin \%83.5'inde 1-3 kişinin hayvanlarla ilgilendiğini belirlenirken, büyük bir bölümünün (\%98.4) aile işgücü ile desteklendiği görülmektedir (Tablo 1). Türkiye'de üreticiler, kendi kendine yeterli, kapalı sistem bir üretim modelini benimsemektedirler (14). İşletmelerdeki aile işgücüne dayalı yetiştiricilik şekli, işgücü verimliliğini artırabilmek ve iş̧̧ilik giderlerini azaltabilmek için yetiştiricilerin başvurdukları ekonomik bir önlemdir. Bu yöntemle, daha az sermaye yatırımı ile üretkenliğin artırıması amaçlanmaktadır. Özellikle kadınlara, çocuklara ve yaşlılara istihdam sağlamaya yardımcı olunmakta$\operatorname{dır}(15,16,17)$. Bu durum hayvan verimi, refahı ve sağlığı gibi konularda olumsuz sonuçlar doğurabilmektedir $(4,18)$.

Katılımcıların yaklaşık \%76'sının 10 yıldan daha uzun süredir manda yetiştiriciliği ile uğraştıkları ve önemli bir tecrübeye sahip oldukları belirlendi (Tablo 1). Bir işletmede personelin tecrübeli olması ve işini severek yapması hayvan refahı ve verimliliği artıran unsurlardır (15). Hayvancılığın sorunlarına rağmen, manda yetiştiricilerinin tecrübeleri ve istikrarlı üretimleri birlikte değerlendirildiğinde; Sivas manda yetiştiriciliğinin gelişimi, iyileştirilmesi ve verimin artırılmasında bu durum avantaj sağlayacaktır.

Katılımcıların manda üretim amaçları; Merkez ilçede ağırlıklı olarak (\%52.9) süt üretimi, Şarkışla (\%53.3) ve Suşehri (\%76.9) ilçelerinde ise kombine (et ve süt) üretim olduğu belirlendi. Yetiştiricilerin üretim tercihleri genel olarak pazar ve pazarlama olanaklarıyla şekillenmektedir. Özellikle Suşehri'nde kombine üretime daha ağırlık verildiği tespit edilmiştir ( $p<0.01)$. Ürün çeşitliliğine dayanan üretim modelleri yetiştiricinin kazancının artmasını sağlayacaktır. Türkiye'de manda yetiştiriciliği, ağırlıklı olarak süt üretimi amacıyla küçük aile işletmelerinde yürütülmektedir $(9,19$, 20 , 21). Örneğin; Bingöl ili manda yetiştiricilerinin \%92.2 oranında süt üretimi amacıyla yetiştiricilik yaptıkları tespit edilmiştir (5). Manda, sığırlardan sonra dünyada süt üretimi amacıyla yetiştiriciliği yapılan ikinci türdür $(17,22)$. Ancak birçok ülkede manda; et, süt, deri üretimi ve çekim hayvanı olarak çok amaçlı yetiştirilmektedir $(4,8,17)$. Filipinlerde yürütülen bir çalışmada, üreticilerinin manda yetiştiriciliğini canlı hayvan satışı (\%94), süt üretimi (\%86), çekiş/güç hizmeti (\%70), gübre satışı (\%39) ve işlenmiş süt ürünleri üretimi (\%3) amacıyla yaptıkları bildirilmiştir (17).

İşletmelerin \%95.1'nin manda ile birlikte sığır yetiştiriciliği de yaptıkları tespit edildi (Tablo 1). Karma üretim modeli hayvancılıkta çok yaygındır. Bu üretim modeliyle, ürün çeşitliliği ve ilave kazanç hedeflenmektedir. Ancak hayvanların bakımı, beslenmesi ve üretkenlik gibi konularda tür öncelikleri dikkate alınması gerekmektedir. Mandalar, sahip oldukları özellikler ve güçlü yapıları sayesinde hastalıklara karşı dayanıklı olsalar da $(8,23,24)$ sığır yetiştirilen işletmelerde, hayvan sağlığını korumak adına koruyucu önlemlerin alınması, aşılama programlarının ve biyogüvenlik uygulamalarının daha dikkatli uygulanması gerekmektedir $(12,25,26)$.

Manda yetiştiriciliği dışında uğraşı alanı sorulan katılımcıların \%5.7'si sadece büyükbaş hayvan yetiştiriciliği, \%54.9'u kanatlı ve büyükbaş hayvan yetiştiriciliği ve $\% 27.9$ bitkisel üretim ile birlikte büyükbaş hayvan yetiştiriciliği yaptıklarını; \%7.4'ü sadece bitkisel üretim ile uğraştıklarını ve bitkisel üretim yanı sıra \%30'u kanatlı ve büyükbaş hayvan yetiştiriciliği de yaptıklarını beyan ettiler (Grafik 1). Çoğunlukla karma üretim (bitkisel ve hayvansal) sistemi biçiminde meydana gelen küçük işletmeler, her iki üretimin bileşimi ile faydalarını optimize etmektedirler. İşletmeler, temelde gelir elde etmek amacının yanı sıra nakit akışı için bitkisel üretim, sermaye kaynağı için hayvancılık yaparak kazanç yollarını çeşitlendirmektedirler (17).

İşletmelerin sığır varlığının; montofon (\%38.9), simental (\%31.8), holştayn (\%5.6) ırkı ve bu ırklarının melezlerinden (\%14.1) oluştuğu belirlendi (Grafik 2). Katılımcılar, bu ırkların yetiştiriciliğini özellikle yetiştirme şartlarına uygun (\%63), verimlerinin yüksek (\%19) ve bakımlarının da kolay olması gibi gerekçelerle tercih ettikleri tespit edildi (Grafik 3). Yetiştirdikleri sığır ırkları $(p<0.05)$ ve bu ırkları tercih sebepleri $(p<0.01)$ bakımından ilçeler arasındaki farklılıklar önemli bulunmuştur. Montofon, simental ve bu ırkların melezlerini yetiştiriciliğinin öne çıkmasında en önemli neden bölge şartlarına, meraya dayalı ekstansif yetiştiricilik koşullarına bu ırkların zamanla uyum sağlamasından kaynaklanmaktadır.

Katılımcılara yöneltilen "Sığır yetiştiriciliği ile karşılaştırıldığında manda yetiştiriciliğinin farklılıkları nelerdir?" sorusunu, Merkez ilçedekiler pazara yakın olmaları ve süt amaçlı üretimleri sebebiyle süt verimi üzerinden değerlendirirken, Şarkışla ve Suşehri ilçelerindeki katılımcıların et üretimi yönüyle soruyu yanıtladıkları görülmektedir (Grafik 4). Katılımcılar, manda sütü ve ürünleri kaliteli, fiyatıda yüksek ancak süt veriminin az olmasını (Merkez \%26.7; Şarkışla \%28.6; Suşehri \%26.1) ortak görüş olarak bildirdiler (Grafik 4). Ancak ikinci ve üçüncü sırada belirtilen görüşler, ilçelere göre değişiklik arz etmektedir. Merkez ilçedeki katılımcılar, mandanın bakımı zor (\%17.8), hastalıklara daha dayanıklı (\%11.1) 
görüşlerini bildirirlerken, Şarkışla ilçesindeki katılımcılar manda hastalıklara dayanıklı (\%17.9), et ve canlı hayvan satış fiyatı düşük (\%14.3) yönünde görüş bildirdiler (Grafik 4). Suşehri ilçesindeki katılımcılar ise, manda eti ve canlı hayvan fiyatı düşük (\%26.1) ve mandanın bakımı kolay (\%15.9) yönünde görüş bildirdiler (Grafik 4). Katılımcıların yetiştirme amaçları ve ilçeler bazında manda yetiştiriciliğinin farklılıkları sorusunda mandanın verimleri, mizacı ve dayanıklılığı gibi konuları vurguladıkları tespit edildi. Bu durumun yetiştiricilerin deneyimleri, çalıştıkları hayvanların mizaçları ile yetiştirme alışkanlıklarının bir sonucu olduğu düşünülmektedir. Mandaların bazı davranışları, diğer evcil geviş getiren hayvanların sergilediği davranışlara benzer gibi görünse de, özellikle sığırlardan ayrılan bazı önemli davranışlara sahiptirler. Bu noktada yetiştiricilere bir bakış açısı kazandırılması faydalı olacaktır. Mandalar, doğal seçilim yoluyla sıcak iklim koşullarına çeşitli morfolojik, fizyolojik ve davranışsal adaptasyonlar geliştirmişlerdir. Yoğun yetiştirme koşullarında kapalı ve bağlı sistemlerde barındırıldıklarında, otlak ve sulak alanlara erişimleri engellendiğinde veya barınak içi alanları kısıtlandığında, mandaların refahı, sağlığı, sosyal davranışları, termoregülasyon ve homeostazis gibi çeşitli fizyolojik mekanizmaları olumsuz etkilenebilmektedir $(4,27,28)$. Bu nedenle, yetiştiricilerin mandanın özellik ve ihtiyaçlarını tanıyarak işletmelerinde mandalar için sığırlardan farklı barındırma, bakım ve besleme koşulları oluşturmalıdırlar $(3,8,29,30)$. Mandalar, tam olarak kültüre alınmamış hayvanlardır. Yetiştiricilerin farklılık olarak vurguladıkları huysuzluklar ile ikili görüşmelerde de dile getirdikleri özellikle mandaların sağım esnasında huysuzluk göstermeleri de mandaların annelik içgüdüsü yüksek hayvanlar olmalarından kaynaklanmaktadır (27). Sağım esnasında bakıcı davranışıları, hayvanlarla konuşma, nazik dokunma, sevme gibi olumlu etkileşimlerin artırılması, mandalarda davranış ve verimlik üzerine büyük bir etkiye sahip olduğu bildirilmiştir $(26,27,31)$. Manda refahını ve verimliliğini artırmak için insan-hayvan etkileşiminin önemini dikkate alarak, bakıcı tutum ve davranışlarını geliştiren eğitim programları düzenlenmelidir (32). Bu bilgilere ek olarak, Türkiye'de manda işletmelerinde sağım işlemlerinin kadınlar tarafından yapılırken, hayvan bakımı ve diğer işlerinin ise işletme sahibi olan erkekler tarafından gerçekleştirildiği unutulmamalıdır (29). Hayvan bakımı ile ilgili düzenlenecek eğitimlerin işletmede hayvanla etkileşime giren tüm bireyleri kapsayacak şekilde yaygınlaştırılması elde edilecek başarıyı artıracaktır.

"Manda yetiştiriciliği ile ilgili herhangi bir toplantı ya da eğitime katıldınız mı?" sorusuna yetiştiricilerin \%37.7'si evet cevabını verdiler (Tablo 2). "Sığır yetiştiriciliği ile ilgili herhangi bir toplantı ya da eğitime katıldınız mı?" sorusuna ise \%16.4'ü evet yanıtını verdiler (Tablo 2). Bu eğitimlerin yetiştiriciliklerine bir katkısı olduğunu düşünen katılımcı oranı $\% 84.3$ olduğu tespit edildi (Tablo 2). Bu konularda eğitimler düzenlenirse yetiştiricilerin \%68.9'u katılmak istediklerini beyan ettiler (Tablo 2). Eğitimde en önemli kazanım bireylerin istekli olmaları ile sağlanmaktadır. Hayvan bakıılarının bilgili olmaları ve hayvana olumlu yaklaşımları ile hayvan refahı, verimlilik ve üretime katkı sağlanacağını bakıcıların eğitiminin önemini ortaya koyan birçok çalışma bulunmaktadır $(14,32,33,34)$.

Hayvancılık hakkında yenilik ve bilgi kaynağı olarak yetiştiricilerin \%34.7'si il-ilçe tarım müdürlüklerinden, \%33.1'i ailelerinde, \%16.5'i damızlık birliklerinde ve \%10.7'si ise medyadan (TV/Gazete/Radyo/Internet) yararlandıklarını beyan ettiler (Tablo 2). Hayvancılıkla ilgili tüm konularda güvenilir bilgi edinme merkezi olarak en fazla diyalog içerisinde oldukları Tarım ve Orman Bakanlığı il ve ilçe müdürlüklerini görmektedirler. Özellikle Merkez'deki yetiştiricilerin il müdürlüğünden daha fazla faydalandıkları tespit edildi $(p<0.001)$. Bunun yanı sıra geçmişten gelen bilgi ve tecrübenin aktarılma kanalı olan ailelerinden ve haber kaynağı olarak damızlık birliklerinden faydalandıkları tespit edildi. Yetiştiricilerin, gelişen bilgi teknolojileri ile bilgiye en kolay ulaşma yolu olarak medyadan da faydalanmaları dikkat çekicidir. IIIilçe tarım ve orman müdürlüklerini hayvancılıkla ilgili yenilik ve bilgi kaynağı olarak görmeleri ile eğitime istekli olmaları birlikte değerlendirildiğinde; bu yetiştiricilik kolunu geliştirmeye yönelik düzenlenecek eğitim programları faydalı olacaktır. Küçük işletmeler, zengin geleneksel bilgi ve uygulamalarının deposudur ve zaman içinde karşılaşılan hem kısıtlamalara hem de fırsatlara yanıt olarak her zaman tarım sistemleri içerisindeki varlıklarını korumuşlardır. Yetiştirici ve kamu işbirliği içerisinde gerçekleştirilecek eğitimler sonucunda, bilgi aktarımı güçlü bir alt yapı oluşturan aile bağları ve sosyal ağların güçlü varlığı sayesinde daha hızlı ve kapsamlı bir yayılım sağlayacaktır $(17,26)$.

Sonuç olarak; manda yetiştiriciliğinin, alternatif bir hayvancılık kolu olmayıp başlı başına bir hayvancılık alanı olduğu ön plana çıkarılmalıdır. İşletmeler, tek bir geçim kaynağı faaliyetine güvenmek yerine, hayvansal (manda, sığır, kanatlı) ve bitkisel üretiminin birlikte yürütüldüğü karma bir üretim modeliyle, karlarını maksimize etmeye çalışmaktadırlar. Katılımcılar, manda yetiştiriciliği ile birlikte özellikle yetiştirme şartlarına uygun, bakımları kolay ve meraya uyumlu olması gibi gerekçelerle tercih ettikleri montofon, simental gibi sığır ırklarının yetiştiriciliğinde ortak uygulamalardan faydalanmaktadırlar. Katılımcıların süt veya et üretimi, yetiştirme yönü ve uğraş alanlarına göre sığır-manda yetiştiriciliği karşılaştırma sorusuna verdikleri yanıtlardaki farklılıklar dikkat çekmektedir. Yetiştiricilik koşulları ile pazar imkanları hayvancılığın üretim yönünü belirleyen iki önemli unsurdur. Bu hayvancılık kolunun gelişimini sağlamak için üretimde özelleşmeye yönelik desteklemelerin faydalı olacağı düşünülmektedir. Mandanın hastalıklara dayanıklı olması yetiştiricilerin, bu yetişitiricilik kolunu sürdürmesinde önemli sebeplerden biridir. Ancak işletmelerde, mandaların sığırlar ile birlikte barındırılmaları sürü sağlığı ve yönetimi açısından bir risk yaratabileceği göz ardı edilmemelidir. Katılımcıların manda mizacının zorluğuna ve süt verimi düşüklüğüne dair serzenişleri dikkate alındığında, yetiştiriciler arasında damızlık hayvan seçiminde mizacın önemli bir unsur olduğu ve bakıcı davranışlarının verimliliği etkilediği bilgilerinin mutlaka yaygınlaştırılması gerekmektedir. Katılımcıların \%34.7'sinin manda yetiştiriciliği konusunda il/ilçe müdürlüklerinden bilgi edinmeye çalışırken yalnızca \%2.5 inin doğrudan profesyonel yardım (veteriner hekim, ziraat mühendisi) aldığı belirlendi. Bunun yanı sıra üreticilerin \%15.7'si katıldıkları eğitim ya da toplantıların yetiştiricilik bilgilerine bir katkısı olmadığı belirtirken, \%68.9'u manda yetiştiriciliği hakkında bir eğitim düzenlenirse katılmak istediklerini ifade ettiler. Yetiştiricilerin yeterli bir bilgiye ve eğitime ulaşamadıkları, eğitime hevesli oldukları, manda üretimi, verimliliği ve davranışları 
konularında bilgi birikimlerinin geliştirilmesine yönelik eğitim programlarının düzenlenmesinin faydalı olacağı kanatine varılmıştır. Özellikle manda ve sığır yetiştiriciliği birlikte yürütüldüğü için, düzenlenecek bu kapsamdaki eğitim programlarının iç içe girmiş hayvancılık alanlarına yayılarak büyükbaş sektöründe de genel bir iyileşme sağlanacağı düşünülmektedir.

\section{TEŞEKKÜR}

Sivas Cumhuriyet Üniversitesi Bilimsel Araştırma Projesi Birimi (CÜBAP) tarafından V-88 nolu proje olarak desteklenmiştir.

\section{KAYNAKLAR}

1. Bernardes O. (2007). Buffaloes Breeding in Brasil. Ital J Anim Sci. 6(2): 162-167.

2. Atasever S, Erdem H. (2008). Manda Yetiştiriciliği ve Türkiye'deki Geleceği. OMÜ Zir Fak Derg. 23(1): 59-64.

3. Sarı̈zkan S. (2011). Türkiye'de Manda Yetiştiriciliği'nin Önemi. Kafkas Üniv Vet Fak Derg. 17(1): 163-166.

4. De La Cruz-Cruz LA, Guerrero-Legarreta I, Ramirez-Necoechea R, et al. (2014). The Behaviour and Productivity of Water Buffalo in Different Breeding Systems: a Review. Vet Med. 59(4): 181-193.

5. Özdemir G, Özdemir A. (2016). Bingöl İli Manda Yetiştiriciliğinin Sorun ve Çözüm Önerilerinin Yetiştirici Gözüyle Değerlendirilmesi. Iğdır Üni. Fen Bilimleri Ens Derg. 6(2): 127-134.

6. Soysal Mi. (2014). Anatolian Water Buffalo Husbandry in Turkey. Proceedings of the International Symposium on Animal Science, September 2014, 147-155, Belgrade-Zemun.

7. Çiftçi S, Yılmaz A. (2019). Bitlis İli Anadolu Mandası İşletmelerinin Genel Yapısal Özellikleri Üzerine Bir Araştırma. ÇOMÜ Zir Fak Derg. 7(1): 47-56.

8. Ermetin O. (2017). Husbandry and Sustainability of Water Buffaloes in Turkey. TURJAF. 5(12): 1673-1682.

9. Borghese A, Mazzi M. (2005). Buffalo population and strategies in the world. In, Borghese A (Ed): Buffalo Production and Research. 1st ed, 1-39, Rome, Italy.

10. T.C. Sivas Valiliği Tarım ve Orman II Müdürlüğü. 2017 Yılı Faaliyet Raporu. Erişim Adresi: https://sivas.tarimorman.gov.tr/Menu/21/Faaliyet-Raporu. Erişim Tarihi: 01.11.2018.

11. Özdamar K. (2013). Paket Programlar ile İstatistiksel Veri Analizi-1. 9. Baskı, Nisan Kitabevi, Ankara.

12. Özdemir G, Özdemir A. (2018). Bingöl Ili Manda İşletmelerinde Bazı Yetiştiricilik Uygulamalarının Biyogüvenlik Kuralları Açısından Değerlendirilmesi. MJAVL. 8(1):1-8.

13. SPSS (2008). SPSS for Windows Release 17.0. SPSS Inc.

14. Özen N, Şayan $Y, A k I$, ve ark. (2010). Hayvansal Üretim Çevre iliş̧kileri ve Organik Hayvancılık. Türkiye Ziraat Mühendisliği 7. Teknik Kongresi, 11-15 Ocak 2010, Ankara.

15. Kılıç i, Bozkurt Z, Tekerli M, ve ark. (2013). Afyonkarahisar ili Koyunculuk İşletmeleri Çalışanlarının Hayvan Refahını Etkileyen Faktörlerle Illgili Algıları. Lalahan Hay Araşt Enst Derg. 53(1): 29-38.

16. Azabağaoğlu MÖ, Hurma H. (2015). Determination of Consumers' Demand on Water Buffalo Products. Social Sciences Research Journal. 3(4): 5-11.

17. Escarcha JF, Lassaa JA, Palacpacb EP, et al. (2020). Livelihoods Transformation and Climate Change Adaptation: The Case of Smallholder Water Buffalo Farmers in The Philippines. Environ Develop. 33:100468.
18. De Rosa G, Grasso F, Braghieri A, et al. (2009). Behavior and Milk Production of Buffalo Cows as Affected by Housing System. J Dairy Sci. 92(3): 907-912.

19. Şekerden Ö, Borghese A, Köroğlu M, ve ark. (2005). Anadolu Mandalarında Sun'i Tohumlama Çalışmaları ve PRID (Progesterone Releasing Intravaginal Device) Uygulamanın Döl Tutma Oranı Üzerine Etkisi. Tarım Bilimleri Derg. 11(2): 126-128.

20. Akbulut Ç, Yazıcı F. (2011). Bafra Kızılırmak Deltasında Elde Edilen Manda Sütlerinin Değerlendirilmesi ve Deltadaki Ekolojik Dengeyi Korumada Önemi. Samsun Sempozyumu, 13-16 Ekim 2011, Samsun.

21. Şahin A, Ulutaş Z, Yıldırım A. (2013). Türkiye ve Dünya'da Manda Yetiştiriciliği. Gaziosmanpaşa Bilimsel Araştırma Dergisi 8: 65-70.

22. Degirmencioglu T, Unal H, Ozbilgin S, et al. (2016). Effect of Ground Fenugreek Seeds (Trigonella foenum-graecum) on Feed Consumption and Milk Performance in Anatolian Water Buffaloes. Arch Anim Breed. 59(3): 345-349.

23. Naveena BM, Kiran M. (2014). Buffalo Meat Quality, Composition, and Processing Characteristics: Contribution to the Global Economy and Nutritional Security. Animal Frontiers. 4(4): 18-24.

24. Deb GK, Nahar TN, Duran PG, et al. (2016). Safe and Sustainable Traditional Production: The Water Buffalo in Asia. Front Environ Sci. 4:38.

25. Şeker I, Tasalı H, Güler H, (2012). Muş illinde Sığır Yetiştiriciliği Yapılan İşletmelerin Yapısal Özellikleri. F Ü Sağ Bil Vet Derg. 26(1): 09-16.

26. Köseman A, Şeker í. (2016). Malatya ilinde Sığırcılık İşletmelerinin Mevcut Durumu: I.Yapısal Özellikler. F Ü Vet Fak Sağ Bil Vet Derg. 30(1): 5-12.

27. Napolitano F, Pacelli C, Grasso F, et al. (2013). The Behaviour and Welfare of Buffaloes (Bubalus bubalis) in Modern Dairy Enterprises. Animal. 7(10): 1704-1713.

28. Sabuncuoglu N, Lacin E, Coban O, Genc M. (2020). Animal Welfare Assessment Based on Welfare Quality ${ }^{\circledR}$ Criteria in a Dairy Farm in Turkey. Dicle Üniv Vet Fak Derg.13(2):157-161.

29. Kaplan Y, Bozkurt Z, Tekerli M. (2018). Evaluation of Water Buffalo Holdings in Yozgat Province in Terms of Environmental Factors Affecting Animal Welfare. Lalahan Hay Araşt Enst Derg. 58(2):67-76.

30. Yáñez-Pizaña A, De la Cruz-Cruz LA, Tarazona-Morales A, et al. (2020). Physiological and Behavioral Changes of Water Buffalo in Hot and Cold Systems. J. Buffalo Sci. 9: 110-120.

31. De Lima Carvalhal MV, Sant'Anna AC, Páscoa AG, et al. (2017). The Relationship Between Water Buffalo Cow Temperament and Milk Yield and Quality Traits. Livest Sci. 198: 109-114.

32. Waiblinger S, Menke C, Coleman G. (2002). The Relationship Between Attitudes, Personal Characteristics and Behavious of Stockpeople and Subsequent Behaviour and Production of Dairy Cows. Appl Anim Behav Sci. 79(3): 195-219.

33. Breuer K, Hemsworth PH, Coleman GJ. (2003). The Effect of Positive or Negarive Handling on the Behavioural and Physiological Responses of Nonlactating Heifers. Appl Anim Behav Sci. 84(1): 3-22.

34. Hemsworth PH. (2003). Human-Animal Interactions in Livestock Production. Appl Anim Behav Sci. 81: 185-9.

\section{Sorumlu Yazar:}

Gökçe ÖZDEMiR

Sivas Cumhuriyet Üniversitesi Veteriner Fakültesi Zootekni Anabilim Dalı, 58140, Sivas, TÜRKIYE E-posta: gokceozdemir@cumhuriyet.edu.tr 